\title{
STUDENTS' EXPERIENCES AND PERCEPTIONS OF ONLINE COLLABORATIVE LEARNING IN HIGHER EDUCATION OF KOREA AND THE UAE
}

\author{
Dr. Jieun LEE \\ ORCID: 0000-0001-5692-9263 \\ School of Education \\ Chosun University \\ Gwangju, SOUTH KOREA \\ Dr. Gihan OSMAN \\ ORCID: 0000-0001-8830-3409 \\ Graduate School of Education \\ American University in Cairo \\ Cairo, EGYPT
}

Received: 29/01/2020 Accepted: 11/05/2020

\begin{abstract}
The purpose of this study was to compare the experiences and perceptions of UAE and Korean students in campus-based universities of online collaborative learning (OCL). 262 college students participated in online surveys. Their experiences in terms of frequency, assessment, barriers, support, and attitude for OCL in each country were examined. With Importance-Performance Analysis, the perceived importance of OCL activities was compared with actual frequency. Both countries' students experienced group projects and group presentations the most frequently, while online collaborative writing and online group exams were rarely used. As barriers to OCL, UAE students pointed out language, gender, and privacy as the major barriers while Korean students mentioned students' attitude and language. UAE students had more frequent experiences of and more positive attitudes toward OCL than did Korean students, although the two countries have similar cultural propensities.
\end{abstract}

Keywords: Online collaborative learning, Korea, UAE, cross-cultural study, IPA.

\section{INTRODUCTION}

According to the OECD, group-based activities and interactions are increasingly regarded as important for the 21st century learner (Martin 2018). Many researchers have pointed out the importance of helping learners develop skills related to team-work, uncertainty, and collaborative knowledge construction all associated with collaborative learning (e.g. Muukkonen \& Lakkala, 2009). Students' development of work-related competencies depends on the "learning environment and its educational methods (Lakkala, Toom, Ilomäki, \& Muukkkonen, 2015, p.521)." A report by the World Bank (2008) suggested that higher education in the Middle East should put greater emphasis on constructivist methodologies, collaborative strategies, studentcentered learning as well as the integration of technology. Similar concerns were shared for other developing countries (Adam, 2003), and even in the USA (Choi, Khamalah, Kim, \& Burg, 2014).

The diffusion of Internet technologies has stimulated the rapid adoption of online collaborative learning (hereafter OCL). Their affordances enable promoting the pedagogical values of collaborative learning (e.g. higher-order thinking, information retention, cognitive reasoning, improved satisfaction, social skills) beyond the limitations of time and place (Oh \& Yoon, 2014). Particularly for campus-based universities, OCL provides learners with the flexibility for extended learning and enables multi-level interactions, resource sharing, and higher-order thinking activities, alongside improving competencies to deal with realworld problems (Oliveira, Tinoca, \& Pereira, 2011). This is It is also associated with developing skills such as 
cross-cultural communication, developing multiple perspectives, and reflective thinking (Choi et al. 2014). OCL would be one of the most demanding but properly prepared online pedagogies in the recent pandemic situation that brings a forced shift to online learning.

Despite the many benefits and potential of OCL, the actual implementation does not always align with its theoretical promises (Osman, Duffy, Chang, \& Lee, 2011), nor do students equally react to such activities (Fung, 2004; Hilliard, Kear, Donelan, \& Heaney, 2020). Also, OCL presents the learner with many challenges (Havard, $\mathrm{Du}, \& \mathrm{Xu}, 2008)$ such as the absence of social context (Hishina, Okada, \& Suzuki, 2005), possible lack of feedback from facilitators or peers, limited time to participate, slow Internet, and low participation (Chang \& Kang, 2016) to name a few.

With advances in technology and the use of social media, and its rapid and massive uptake by young people everywhere, the geographical distances are bridged virtually. Also, internationalization efforts, manifested in student exchange and faculty mobility as well as MOOC offerings, are also increasing cross-cultural communication. As the OCL environment becomes multicultural or transnational, there is a strong need for research on what students from different cultures experience with OCL and how they perceive it. Culturally relevant pedagogy and teaching should be implemented fairly even for the underserved culture (Adams, Rodriquez, \& Zimmer, 2019). However, cultural differences have been often tackled superficially in the literature and have lacked empirical supports (Al-Harthi, 2010). Some cultures are also under-represented, and often misunderstood. Examples of these would be Middle Eastern and Asian countries, other than China. Not only are these cultures often stereotyped, but they are also often depicted as a homogeneous entity. It is tenacious to assert that China and Korea in Far East Asia hold similar cultural values. Although the two countries have similar collectivistic propensity, China has very different cultural values than Korea in 'uncertainty avoidance' (Culture Compass ${ }^{\mathrm{TM}}$, 2019). Therefore, generic statements about 'Asian learners' or 'Middle Eastern learners' should be treated with caution (Sawir, 2005). As Sawir (2005) suggested, inquiry into students' prior learning experiences and their beliefs about learning should be undertaken, in order to gain a more complete understanding of the students.

Previous studies noted that few empirical studies have examined several aspects of online collaboration from a cross-cultural perspective ( $\mathrm{Zhu}, 2012$ ). There is also a need for research examining cultural influence on OCL in broader contexts other than China and USA (Uzuner, 2009; Zhu, 2012). South Korea is the third-ranked place of origin of international students, and students from the Middle East constitute almost $10 \%$ of all international students in the US (IIE, 2018). These under-represented student groups are major international student populations in western universities. It is crucial to understand how these student groups experience online collaborative learning where these groups are major places of origin of international students. Also, Korea and the UAE need to establish a clear mutual understanding in terms of their online learning experiences for their future partnership in the tertiary education field (Human Resources Development Service of Korea, 2019).

To address these needs mentioned above, the following questions were put forth: (1) How do students in Korea and the UAE experience online collaborative learning activities in higher education? (2) How do students in the two countries perceive online collaborative learning? (3) Are there differences between the reported use and perceived importance of online collaborative learning activities in Korea and the UAE?

\section{LITERATURE REVIEW}

\section{Culture and Prior Learning Experience in OCL}

OCL has become accepted as a pedagogically effective strategy for tertiary education (Oye et al., 2014; Hilliard et al., 2020). Previous studies confirmed its several benefits that could often render it superior to face-to-face collaboration; student engagement is more intense and equally distributed among learners (Angeli, Valanides, \& Bonk, 2003), and online collaboration in the form of asynchronous discussions enhances student learning achievement (Young, 2000) by adding flexibility of place and time. It is suggested that online can be a medium for "true collaborative work" since there is little social pressure and greater freedom for learners to express their ideas through more reflective and effective communication (Henri \& Rigault, 1996). 
Student's and teacher's attitude towards online learning influence its adoption and use, and culture impacts those perceptions (Jung, 2014). Culture may play an important role in the online learning environment (Uzuner, 2009). Previous studies indicate that students from diverse cultures vary in how they behave online (Kim \& Bonk, 2002) and in their satisfaction with online learning activities (Gunawardena, 1998; Hannon \& D'Netto, 2007). For example, Ramiah (2014) reported that American students prefer e-learning while Asians are not likely to actively participate in online discussion and assessment. By comparing factors affecting the adoption of e-learning systems between USA and Qatar, El-Masri and Tarhini (2017) asserted that the attitude in developing countries differs from in developed ones. Other than the degree of a country's development, several researches have used some indices drawn from Hofstede's cultural dimensions as a framework to understand students' culture. Wang (2007) and Selinger (2004) used 'power distance' to examine its influence on student learning. Some studies suggested that individualism fits more with online communication than collectivism. Collectivistic learners are more group-oriented (Chang \& Lim, 2002) and consider relationships to be more important than the task (Trumbull, Rothstein-Fisch, \& Greenfield, 2000). In terms of online communication, they try to understand meaning through nonverbal language, while individualistic learners will rely mostly on the words exchanged (Hall, 1976). In individualistic societies, collaboration is a process of the search for solutions. In collectivist societies, on the other hand, an individual may fail to differentiate between her work and the result of group activities. The process of grouping and re-grouping would be more difficult in collectivist than in individualistic cultures (Economides, 2008). However, these assertions from previous studies may not be plausible without understanding students' prior learning experiences, one of the critical sources to represent the current attitude toward learning (Sawir, 2005). In sum, it is critical to understand student group's learning experiences embedded in a certain cultural context. A recent study reported that the dropout rates of the learners from low context culture are greater than in high context culture (Bozkurt \& Akbulut, 2019). In sum, culture of learners is a critical component to expect or predict online learning outcomes and engagement.

\section{Experiences around Communication, Barriers, Support, and Assessment in OCL}

Students' beliefs about learning are rooted in their prior learning experiences (Sawir, 2005). Some of the most memorable and influential experiences are those related to assessment since what is assessed is what is valued in a learning context (Swan, Shen, \& Hiltz, 2006). Assessment has been regarded as the engine driving and shaping student online collaborative activity (Swan, Shen, \& Hiltz, 2006) and a way of ensuring participation in online collaboration (Brindley, Walti, \& Blaschke, 2009). It will impact the development of online collaborative skills indirectly. Some issues around the assessment of collaboration lie in the complexity of assessing both individual and group collaboration. To encourage collaboration, both individual and group effort must be appropriately assessed since it can maintain individual accountability and also positive interdependence (Johnson \& Johnson, 1986). Unfortunately, the examples that implement both individual and group assessment in online collaborative learning are not frequently observed (Swan, Shen, \& Hiltz, 2006). Alignment between task and assessment is critical also for online courses (Adams, Rodriquez, \& Zimmer, 2019). Compared to face-to-face instructional design, online learning design is relatively lacking alignment between assessment and learning objectives since online learning puts more focus on values of access and content management rather than on pedagogy (Hannon \& D'Netto, 2007).

In OCL, students are expected to work in a team effectively, which requires, for example, team work, negotiation, group decision making, project management skills, and handling some technical issues. The whole process of OCL requires practice and time to develop. To nurture these skills, instructional supports are critical. Thorpe (2002) strongly suggested re-conceptualization of the term 'learner support' in online learning since all online learners should be supported, as there are exceptional needs compared to offline. Support from instructors or institutions can help create a more safe and effective learning environment for all learners by reducing hassles, anxiety, and inconvenience (Moore \& Kearsley, 2011).

One of the challenges online is the absence of contextual cues found in face-to-face communication (Chang $\&$ Lim 2002). Hannon and D'Netto (2007) found that local students whose first language was English had significantly more positive perceptions of online courses and higher mean scores when compared with international students whose first language was not English. Moreover, for students to communicate 
clearly online, they must be familiar with the language of a discipline (Macdonald, 2003) in addition to the language of instruction. Although Palloff and Pratt (1999) argue that online environment neutralizes learners' cultural, ethnic, or social conditions, there is an opposite position asserting that online environment plays a role as an escalator to enlarge those cultural differences such as languages (Hannon \& D'Netto, 2007). Bates (2015) underscores that importance of realizing that learners collaborating online might be struggling with the language. As globalization in education has expanded, the number of students studying in English has grown. Language difficulties involve different concerns over colloquial language, writing difficulties, and problems of interpretation (Sawir, 2005).

Taken together, these results indicate that students engaged in collaborative learning may have completely different expectations in diverse cultures and also due to different prior OCL experiences. It is critical for instructors to consider the differences of students toward OCL, which enables to design an optimized learning environment and to plan adequate supports.

\section{METHODS}

\section{Participants and Context}

262 college students participated in the study between November 2015 to January 2016, including 210 from Korea and 52 from the UAE. To recruit participants, the authors contacted 10 instructors working in 10 different colleges in Korea and 9 instructors in 5 colleges in the UAE. The instructors were asked to encourage their students to participate in the online survey. After screening the data, three unsuitable cases were deleted. Participating students in Korea were all Koreans, whilst in the UAE, 62\% were Emiratis (UAE nationals); the rest were from Egypt, Sudan, Canada, Palestine, and 8 other countries. The diversity of nationality in the UAE and the homogeneity in Korean participants reflected the current student composition in higher education of each country. All universities targeted for this study were campus-based.

Table 1. Information of participants $(\mathrm{n}=259)$

\begin{tabular}{|c|c|c|}
\hline & Korea $(n=208)$ & UAE $(n=51)$ \\
\hline \multirow[t]{14}{*}{ Nationality } & Koreans $(n=208,100 \%)$ & UAE $(n=31,60 \%)$ \\
\hline & & Egypt $(n=3,6 \%)$ \\
\hline & & Canada $(n=2,4 \%)$ \\
\hline & & Pakistan $(n=2,4 \%)$ \\
\hline & & Palestine $(n=2,4 \%)$ \\
\hline & & Sudan $(n=2,4 \%)$ \\
\hline & & USA $(n=2,4 \%)$ \\
\hline & & Ghana $(n=1,2 \%)$ \\
\hline & & India $(n=1,2 \%)$ \\
\hline & & Indonesia $(n=1,2 \%)$ \\
\hline & & Jordan (n=1, 2\%) \\
\hline & & Syria $(n=1,2 \%)$ \\
\hline & & Uzbek ( $n=1,2 \%)$ \\
\hline & & Yemen $(n=1,2 \%)$ \\
\hline \multirow[t]{2}{*}{ Gender } & Male $(n=63,30.3 \%)$ & Male $(n=16,31.4 \%)$ \\
\hline & Female $(n=145,69.70 \%)$ & Female $(n=35,68.6 \%)$ \\
\hline Age & Mean $22.3(\mathrm{SD}=5.54)$ & Mean $24.6(\mathrm{SD}=5.59)$ \\
\hline \multirow[t]{6}{*}{ Major } & Education $(n=132,63.5 \%)$ & Design $(n=18,35.3 \%)$ \\
\hline & Engineering $(n=48,23.1 \%)$ & Int'| Relations ( $n=15,29.4 \%)$ \\
\hline & Computer Science $(n=8,3.8 \%)$ & Education $(n=5,9.8 \%)$ \\
\hline & Design $(n=5,2.4 \%)$ & Business Management $(n=4,7.8 \%)$ \\
\hline & Library Science $(n=4,1.9 \%)$ & Computer Science $(n=3,5.9 \%)$ \\
\hline & Others $(n=11,5.3 \%)$ & Others $(n=6,11.8 \%)$ \\
\hline
\end{tabular}


Korea is an East Asian country, speaking Korean, mostly with a racially homogeneous student population in higher education. The UAE is an Arab country located in the Arabian Peninsula. About $10 \%$ of the population is Emiratis, whereas most of the rest are multi-cultural expatriate workers and their families. Although Arabic is the official language of the country, English is more widely spoken. UAE students are exposed to other cultures and educational contexts, especially with a majority of expatriate faculty (Madsen \& Cook, 2010). According to Hofstede (1986) and Hofstede Insights (2018), Korea and the UAE have a similar cultural propensity toward his four dimensions (collectivism-individualism, femininity-masculinity, power distance, and uncertainty avoidance). However, there is a slight difference in that Korea is characterized by having smaller power distance, more collectivism, more femininity, and slightly stronger uncertainty avoidance than the UAE (see Figure 1).

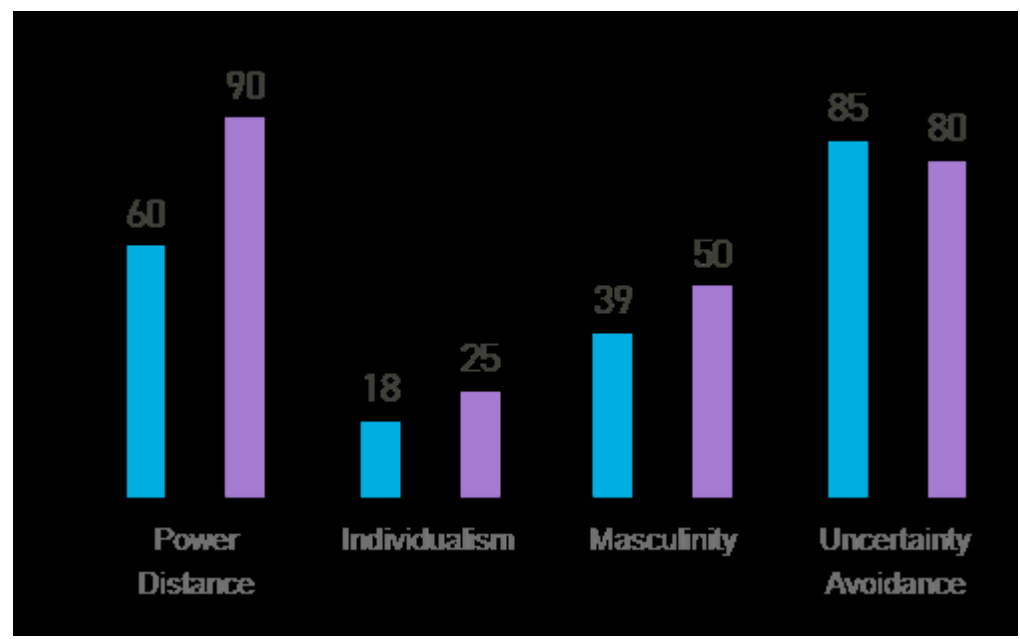

Note: Left bar (blue) is Korea and right bar (purple) is the UAE.

Figure 1. Cultural Beliefs of Korea and the UAE

Source: https://www.hofstede-insights.com/country-comparison

\section{Instrument}

The survey questionnaire consisted of 48 items in three sections. As it was hard to find the appropriate existing survey questionnaire that fit our purpose, the questionnaire was developed by referencing several existing surveys, which were designed to ask about perceptions of instructional innovations (Zhu \& Engels, 2014) and online learning issues (Magjuka, Shi, \& Bonk, 2005). The list of specific OCL activities were established from the one on one interviews with 9 instructors from the UAE and 10 from Korea, which was one of the data collection methods for another research by the authors (in review). The first section had 5 questions to collect demographic information. The second contained 21 items to elicit students' experiences and perceptions of OCL regarding frequency, communication tools, beliefs, barriers, support, and assessment. The third consisted of 22 items that collected actual frequency usage of collaborative learning activities versus perceived pedagogical importance. The instrument was developed in English and Korean. For the reliability of the two versions, the Korean version was translated back into English, compared with the English version, and corrected where there were inconsistencies. The reliability of the instrument was high $($ Cronbach alpha $=.821)$.

\section{Data Analysis}

The survey data were analysed using SPSS 21.0. To examine the mean difference between Korean and UAE students in terms of the experience and perception of OCL, Welch's t-test was conducted. It could address the unequal sample size problems since it may increase the probability of Type 1 error and lower the statistical power (Fraenkle \& Wallen, 2011). To answer the third research question, an ImportancePerformance Analysis was performed. 


\section{RESULTS}

\section{Experience with OCL}

The participants were asked to answer the number of courses that employed OCL in the current semester. UAE students seemed to have more courses with OCL components than Korean students had and were required to spend more hours on online communication. There were significant differences in the number of courses having online collaborative components $(t=-2.29, p=.024)$ and the time spent for online communication $(t=-2.88, p=.001)$.

Table 2. Number of courses with online collaborative learning and hours on online communication

\begin{tabular}{|c|c|c|c|c|c|}
\hline & & $M$ & $S D$ & $t$ & $D f$ \\
\hline \multirow{2}{*}{ No. of Courses/term } & Korea & 2.57 & 1.58 & \multirow{2}{*}{$-2.29 *$} & \multirow{2}{*}{76.307} \\
\hline & UAE & 3.12 & 1.50 & & \\
\hline \multirow[b]{2}{*}{ Hrs. of online communication/week } & Korea & 1.53 & .79 & \multirow[b]{2}{*}{$-2.88^{*}$} & \multirow[b]{2}{*}{63.745} \\
\hline & UAE & 1.96 & .98 & & \\
\hline
\end{tabular}

* denotes that the tvalue is significant at .01 .

\section{Communication Tools for OCL with Peers}

The students were asked to choose up to three tools that their instructors required them to use for online communication. Course messages (e.g., emails) and discussion boards were frequently used in both countries. Korean courses rarely used synchronous meeting tools, blogs, and wikis, whereas the UAE courses used them more frequently. The chat tool is the most frequently used in Korea and course messages were the most frequently used in the UAE.

Table 3. Communication tools for online collaboration

\begin{tabular}{lllll}
\hline \multirow{2}{*}{ Communication Tools } & \multicolumn{2}{l}{ Korea } & \multicolumn{2}{c}{ UAE } \\
\cline { 2 - 5 } & $\mathrm{n}$ & $\%$ & $\mathrm{~N}$ & $\%$ \\
\hline Synchronous meetings (e.g. Google Hangout, Skype) & 11 & 3.09 & 11 & 12.79 \\
Blogs & 14 & 3.93 & 8 & 9.30 \\
Wikis & 5 & 1.40 & 2 & 2.33 \\
Course messages (email) & 101 & 28.37 & 27 & 31.40 \\
Discussion boards of LMS & 43 & 12.08 & 26 & 30.23 \\
Chats (e.g. Whatsapp in the UAE, Kakaotalk in Korea) & 182 & 51.12 & 12 & 13.95 \\
TOTAL & 356 & 100 & 86 & 100 \\
\hline
\end{tabular}

\section{Barriers to Online Collaborative Learning}

As the major barrier to OCL, UAE students chose language whilst Korean students selected students' attitude toward working with peers. In terms of privacy issues, UAE students showed much more concern than Koreans. Regarding gender, most Koreans did not care at all, while UAE students mentioned it as a barrier (12\%). Both countries pointed out that students' attitude and lack of collaboration skills can negatively influence online collaboration. Compared to Korea, UAE students showed more concern over the technology skills of students and instructors as well as infrastructure. 
Table 4. Barriers to online collaborative learning

\begin{tabular}{lllll}
\hline \multirow{2}{*}{ Barriers } & Korea & UAE & \\
\cline { 2 - 5 } & $\mathrm{n}$ & $\%$ & $\mathrm{n}$ & $\%$ \\
\hline Language & 33 & 16.6 & 26 & 63.4 \\
Gender issues & 1 & 0.5 & 5 & 12.2 \\
Privacy & 30 & 15.1 & 11 & 26.8 \\
Attitude toward working with peers & 151 & 75.9 & 18 & 43.9 \\
Collaboration skills & 80 & 40.2 & 19 & 46.3 \\
Student technology skills & 28 & 14.1 & 24 & 58.5 \\
Instructor technology skills & 19 & 9.5 & 13 & 31.7 \\
Infrastructure (e.g., Internet speed, computer specs) & 38 & 19.1 & 15 & 28.3 \\
\hline
\end{tabular}

\section{Assessment and Support of Online Collaborative Learning}

Korean students experienced more courses that do not tie performance in collaboration to grades or that combine group scores with individual scores, if the courses tie collaborative activities to grade. It seems that instructors in the UAE are more likely to give a group grade but not an individual grade for the OCL. OCL in both countries is not being implemented with well-designed assessments that encourage individual responsibility as well as positive interdependence in groups. Also, assessments of OCL activities are largely focused on outcomes, and not on process.

Table 5. Assessment of online collaborative learning

\begin{tabular}{lllllll}
\hline Items & \multicolumn{7}{c}{ Korea } & \multicolumn{3}{c}{ UAE } & & \\
\cline { 2 - 7 } & $m$ & sd & $m$ & sd & $t$ & $d f$ \\
\hline $\begin{array}{l}\text { Performance on collaborative activities is tied to } \\
\text { course grades. }\end{array}$ & 2.32 & .89 & 2.70 & .84 & $-2.75^{*}$ & 257 \\
$\begin{array}{l}\text { The instructor evaluates the product of online } \\
\text { activities and not the process. }\end{array}$ & & & & & \\
$\begin{array}{l}\text { The instructor gives a group grade but not an } \\
\text { individual one. }\end{array}$ & 2.49 & .85 & 2.50 & .80 & -.07 & 257 \\
\hline
\end{tabular}

*Note: Those questions were asked with a 4-point Likert scale ranging from $4=$ True for all courses to $1=$ True of no course.

In all the items related to the instructor and technical support, there were statistically significant differences, with more support provided in the UAE than in Korea. UAE students showed more concern over lack of technology skills. Regarding team conflicts, UAE instructors seemed more likely to address them than did their Korean counterparts. 
Table 6. Support of online collaborative learning

\begin{tabular}{|c|c|c|c|c|c|c|c|}
\hline & \multirow{2}{*}{ Items } & \multicolumn{2}{|c|}{ Korea } & \multicolumn{4}{|l|}{ UAE } \\
\hline & & $m$ & sd & $m$ & sd & $T$ & $d f$ \\
\hline \multirow{2}{*}{$\begin{array}{l}\text { Instructor } \\
\text { Support }\end{array}$} & $\begin{array}{l}\text { The instructor provides support to students that } \\
\text { face conflicts within teams. }\end{array}$ & 2.09 & .91 & 3.05 & 66 & $-8.55^{*}$ & 101.77 \\
\hline & We are given training on how to work as a group. & 2.19 & .85 & 2.59 & .84 & $-3.05^{*}$ & 257 \\
\hline \multirow[t]{2}{*}{ Tech Support } & $\begin{array}{l}\text { We are provided with the necessary technology } \\
\text { training to use online collaboration tools. }\end{array}$ & 2.02 & .87 & 2.70 & .84 & $-5.04^{*}$ & 257 \\
\hline & Technical support is available whenever needed. & 2.00 & .88 & 2.49 & .86 & $-3.60^{*}$ & 257 \\
\hline
\end{tabular}

*Note: Those questions were asked with a 4-point Likert scale ranging from $4=$ True for all courses to $1=$ True of no course.

\section{Attitude toward Online Collaborative Learning}

The most noticeable difference is in the item, "I'd rather meet up with colleagues...than meet online." Korean students strongly prefer meeting in-person to meeting online. Also, they more strongly agree with "Online communication leads to misunderstandings" and "It bothers me when my teammates do not respond..." than UAE students. Another big difference appeared in the item, "I feel comfortable to express ... online." Taken these results together, it seems UAE students feel much more comfortable in communicating and working online than Korean students. Regarding feedback from instructor and peers in OCL, Korean students appreciated it more than UAE students did. However, UAE students expressed a more positive stance about assessment in OCL.

Table 7. Perceptions toward online collaborative learning

\begin{tabular}{|c|c|c|c|c|c|c|}
\hline & \multirow{2}{*}{ Items } & \multirow{2}{*}{$\begin{array}{l}\text { Korea } \\
m\end{array}$} & \multicolumn{2}{|c|}{ UAE } & \multirow[b]{2}{*}{$S d$} & \multirow[b]{2}{*}{$t$} \\
\hline & & & $s d$ & $m$ & & \\
\hline \multirow{6}{*}{ 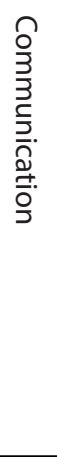 } & $\begin{array}{l}\text { I would rather meet up with colleagues to work on a project than } \\
\text { meet online. }\end{array}$ & 3.22 & .81 & 2.07 & .88 & $8.94^{*}$ \\
\hline & $\begin{array}{l}\text { I feel comfortable to express different ideas and question others } \\
\text { online. }\end{array}$ & 2.48 & .82 & 3.30 & .68 & $-7.39 *$ \\
\hline & Online communication leads to misunderstandings. & 3.00 & .72 & 2.48 & .93 & $3.76^{*}$ \\
\hline & $\begin{array}{l}\text { Not everyone knows how to communicate their ideas clearly } \\
\text { online. }\end{array}$ & 3.14 & .59 & 3.41 & .73 & $-2.77^{*}$ \\
\hline & $\begin{array}{l}\text { It bothers me when my teammates do not respond to my online } \\
\text { communications. }\end{array}$ & 3.35 & .71 & 2.62 & .75 & $6.57^{*}$ \\
\hline & It is easier to reach consensus online. & 2.27 & .71 & 2.93 & .76 & $-5.83^{*}$ \\
\hline \multirow{2}{*}{ 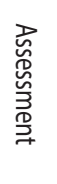 } & $\begin{array}{l}\text { Working online allows the instructor to better judge individual } \\
\text { contributions of team members since the system archives all the } \\
\text { activities. }\end{array}$ & 2.52 & .76 & 2.95 & .82 & $-3.58^{*}$ \\
\hline & Grades on online collaborative activities are fairer. & 2.15 & .76 & 2.28 & .97 & -0.86 \\
\hline \multirow{2}{*}{ 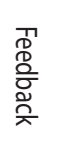 } & $\begin{array}{l}\text { Instructor feedback on our online collaborative groupwork } \\
\text { performance is important. }\end{array}$ & 3.14 & .65 & 2.89 & .96 & $1.78^{*}$ \\
\hline & $\begin{array}{l}\text { Reading the online contributions/comments of others helps me } \\
\text { understand the content better. }\end{array}$ & 2.90 & .63 & 2.80 & .81 & 0.84 \\
\hline
\end{tabular}

*Note: The questions were asked with a 4-point Likert scale ranging from $4=$ strongly agree to $1=$ strongly disagree. 


\section{Differences between Frequency and Importance of Online Collaborative Learning Experiences}

\section{Frequency of Use of OCL Activities}

There are significant differences in the frequency of use of group discussion, understanding course content through group discussion, group practice exercise, collaborative writing, and knowledge sharing (see Table 8). Except for peer review and collaborative data collection and analysis, most of the other collaborative learning activities were used more frequently in the UAE than in Korea. Largely it seems that UAE students experienced all the other collaborative learning activities more frequently than Korean students.

Only two activities, peer feedback and collaborative data collection, were used more frequently in Korea than in the UAE. Group exams and collaborative writing were the least used in both contexts.

Table 8. t-Test of use \& importance of OCL activities between Korean and the UAE

\begin{tabular}{|c|c|c|c|c|c|c|c|}
\hline \multirow[b]{2}{*}{ OCL activities } & \multirow[b]{2}{*}{ Country } & \multicolumn{3}{|c|}{ Use } & \multicolumn{3}{|c|}{ Importance } \\
\hline & & M & Sd & $t$ & $M$ & Sd & $\boldsymbol{t}$ \\
\hline \multirow{2}{*}{ a. Group project } & Korea & 2.67 & .85 & \multirow{2}{*}{-1.67} & 2.60 & .83 & \multirow{2}{*}{$-2.65^{*}$} \\
\hline & UAE & 2.85 & .65 & & 2.92 & .76 & \\
\hline \multirow{2}{*}{ b. Group discussion } & Korea & 2.54 & .83 & \multirow{2}{*}{$-2.87^{*}$} & 2.65 & .82 & \multirow{2}{*}{-.47} \\
\hline & UAE & 2.86 & .68 & & 2.71 & .85 & \\
\hline \multirow{2}{*}{ c. Understanding course content } & Korea & 2.46 & .79 & \multirow{2}{*}{$-5.65^{*}$} & 2.78 & .79 & \multirow{2}{*}{-2.00} \\
\hline & UAE & 3.05 & .63 & & 3.00 & .69 & \\
\hline \multirow{2}{*}{ d. Practice exercise } & Korea & 2.33 & .81 & \multirow{2}{*}{$-5.03^{*}$} & 2.71 & .81 & \multirow{2}{*}{$-6.39^{*}$} \\
\hline & UAE & 2.88 & .67 & & 3.37 & .61 & \\
\hline \multirow{2}{*}{ e. Group exam } & Korea & 1.95 & .88 & \multirow{2}{*}{-1.50} & 2.16 & .91 & \multirow{2}{*}{$-2.93^{*}$} \\
\hline & UAE & 2.16 & .84 & & 2.58 & .95 & \\
\hline \multirow{2}{*}{ f. Group presentation } & Korea & 2.83 & .83 & \multirow{2}{*}{-.95} & 2.73 & .95 & \multirow{2}{*}{-1.88} \\
\hline & UAE & 2.95 & .85 & & 2.97 & .81 & \\
\hline \multirow{2}{*}{ g. Collaborative writing } & Korea & 2.02 & .87 & \multirow{2}{*}{$-3.18^{*}$} & 2.22 & .91 & \multirow{2}{*}{-1.91} \\
\hline & UAE & 2.41 & .77 & & 2.49 & .86 & \\
\hline \multirow{2}{*}{ h. Group reflection } & Korea & 2.23 & .81 & \multirow{2}{*}{-2.17} & 2.55 & .87 & \multirow{2}{*}{$-2.35^{*}$} \\
\hline & UAE & 2.50 & .80 & & 2.86 & .85 & \\
\hline \multirow{2}{*}{ i. Peer review } & Korea & 2.51 & .85 & \multirow{2}{*}{1.36} & 2.84 & .87 & \multirow{2}{*}{1.81} \\
\hline & UAE & 2.33 & .93 & & 2.59 & .86 & \\
\hline \multirow{2}{*}{ j. Knowledge sharing } & Korea & 2.69 & .81 & \multirow{2}{*}{$-3.35^{*}$} & 3.00 & .79 & 01 \\
\hline & UAE & 3.05 & .66 & & 3.00 & .69 & .04 \\
\hline \& Collaborative data collection & Korea & 2.75 & .87 & 127 & 2.89 & .82 & $232 *$ \\
\hline K. Collanorative Gata collection & UAE & 2.58 & .80 & 1.27 & 2.59 & .84 & 2.35 \\
\hline
\end{tabular}

\section{Importance of Use of OCL Activities}

It seems that UAE students perceive most of the collaborative learning activities as more important than Korean students except for peer review, knowledge sharing, and collaborative data collection. Practice exercises was the activity that was perceived as the most important by UAE students, followed by understanding course content through group discussion and knowledge sharing. Group reflection in the UAE needs to be focused while it was not regarded as important in Korea. Group discussion in both countries was more frequently used than its importance. The activities that need to be more focused on are practice exercises in Korea and group reflection in the UAE. 


\section{Importance-Practice Analysis of OCL Activities in Korea and the UAE}

The participants thought that practice exercises in Korea and group reflection in the UAE should be implemented with more frequency. Group exams and collaborative writing were regarded as a low priority and rarely implemented in both countries. These activities belong to the 'Low priority' quadrant. Group discussion is commonly regarded as a 'too-much-used-but-with low-importance' activity in both countries. The activities such as 'understanding course content,' 'group presentation,' and 'knowledge sharing' were those that were currently implemented appropriately and also need to be maintained in Korea and the UAE.

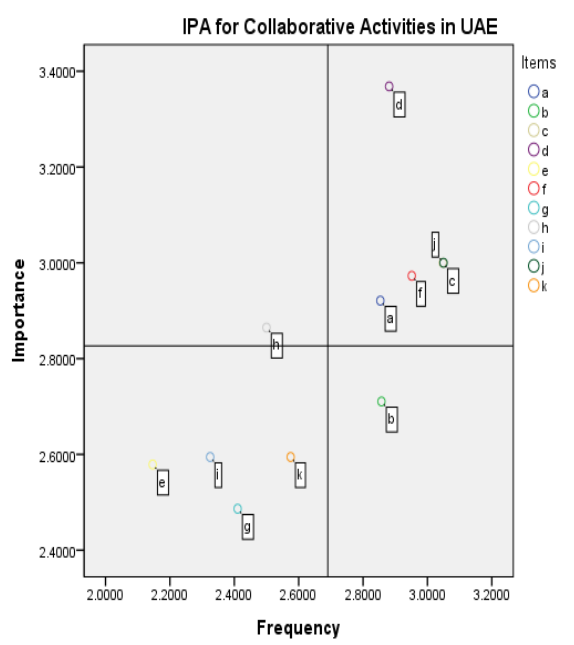

Korea

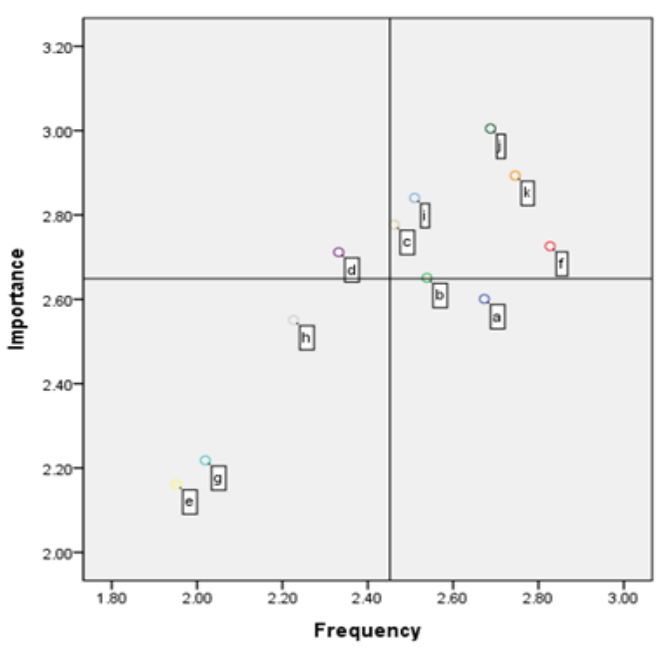

UAE

Figure 2. IPA quadrants of online collaborative activities in Korea and the UAE

Table 9. Online collaborative learning activities by IP analysis

\begin{tabular}{llll}
\hline I-P area & \multicolumn{1}{c}{ Online Collaborative Activities } & & \\
\cline { 2 - 4 } & Korea & Common & UAE \\
\hline $\begin{array}{l}\text { I. Concentrate here } \\
\text { (Low P, High I) }\end{array}$ & $\mathrm{d}$ (practice exercise) & $\mathrm{h}$ (group reflection) \\
\hline $\begin{array}{l}\text { II. Keep up the good work } \\
\text { (High P, High, I) }\end{array}$ & $\begin{array}{l}\mathrm{c}, \mathrm{f}, \mathrm{i}, \mathrm{j}, \mathrm{k} \\
\text { (understanding course content, } \\
\text { presentation, peer review, } \\
\text { knowledge sharing, coll. data } \\
\text { collection) }\end{array}$ & $\mathrm{c}, \mathrm{f}, \mathrm{j}$ & $\begin{array}{l}\mathrm{a}, \mathrm{c}, \mathrm{d}, \mathrm{f}, \mathrm{j} \\
\text { (group project, understanding } \\
\text { course content, practice, } \\
\text { presentation, knowledge sharing) }\end{array}$ \\
\hline $\begin{array}{l}\text { III. Low priority } \\
\text { (Low P, Low I) }\end{array}$ & $\begin{array}{l}\mathrm{e}, \mathrm{g}, \mathrm{h} \text { (group exam, coll. writing, } \\
\text { group reflection) }\end{array}$ & $\mathrm{e}, \mathrm{g}$ & $\begin{array}{l}\mathrm{e}, \mathrm{g}, \mathrm{i}, \mathrm{k} \text { (group exam, coll. writing, } \\
\text { peer review, coll. data collection) }\end{array}$ \\
\hline $\begin{array}{l}\text { IV. Possible overkill } \\
\text { (High P, Low I) }\end{array}$ & $\begin{array}{l}\text { a, b (group project, group } \\
\text { discussion) }\end{array}$ & $\mathrm{b}$ & $\mathrm{b}$ (group discussion) \\
\hline
\end{tabular}

\section{CONCLUSION AND DISCUSSION}

The importance of inquiry into students' perception and experiences with online collaboration lies in that collaborative learning will be more successful when learners value it (Swan et al., 2006). This study investigated college students' perceptions and experiences of OCL in Korea and the UAE and also analysed each country's current practice and the perceived importance of several OCL activities.

The results of this study show that OCL is implemented in a considerable number of courses offered by the campus-based universities in both countries. Although the proportion of courses that should contain online 
collaboration would vary by context and the overall program outcomes, the picture presented by this study shows landscapes not entirely dominated by lecturing, which is a shift from the stereotypical depiction of traditional Eastern contexts, dominated by the persona of the all-knowing instructor (Al-Adwan \& Smedley, 2012). Regarding the communication tools for OCL, it is not surprising that e-mail and discussion boards are frequently used since these are the more traditional and older forms of online communication that both students and instructors are well familiar with. However, noteworthy of observation is the dominance of synchronous tools in both contexts, where informal chatting apps constitute more than $50 \%$ of communication in the Korean context, and to a lesser extent among UAE students, thereby underscoring the potential of social media for online collaborative work for the new generations (Abdul Khalek, 2014). Kakaotalk, an SNS communication app, is widely used in Korea at every age level of population and is being utilized for educational purposes, such as a learning environment for the writing of second language (Lee et al., 2016). With its pervasiveness and enjoyable leisure activities for young people (Erstad, Gilje, \& de Lange, 2007), the SNS app is being considered and actively explored as an innovative educational platform.

However, there are several points that show significant differences. Overall, UAE students had a more positive attitude toward OCL than Korean students in terms of communication, assessment, and feedback despite its shorter history of online learning. Regardless of cumulative research affirming educational effects of collaborative learning (Slavin, 1991), it is not appreciated by many Korean college students (Lee, 2014), who try not to enroll in courses with collaborative tasks. Korean students reported that not many courses that they experience tied OCL performance with course grades. Considering group work naturally entails substantial team work (Kirschner, Paas \& Kirschner, 2009) in addition to the cognitive load generated by learning, students appreciate and persist with group learning only when they are appropriately compensated for their effort. What is assessed tends to be more valued by students (Swan, Shen, \& Hiltz, 2006). UAE students perceived assessment online as much fairer than Korean students. This might be grounded in that Korean instructors are likely to give a group grade but not an individual one in OCL and to assess largely group outcomes, rather than the process (see Table 5), which can implicitly allow free riders in group work (Lee, 2014). This is also true to other countries. Some learners may experience a various range of unpleasant emotions and feelings such as anxiety and frustration when they work with unknown others (Hilliard et al., 2020). However, the fairness of grades of online performance was not positively evaluated by the participants in both countries. Clear and detailed criteria of online performance would lessen students' worries over fairness of grades (Swan, Shen, \& Hiltz, 2006). Therefore, a well-designed assessment scheme that encourages individual responsibility and positive interdependence among teammates (Johnson \& Johnson, 1986; Child \& Shaw, 2016) should be adopted for sustainable online collaborative learning.

In addition, UAE students regarded OCL as more important and experienced it more frequently than Korean students. Since the UAE is more multicultural in student composition in tertiary education, and has gender segregation in face to face classes, OCL may be more welcomed (Al-Fadhli, 2008) than in Korea, a quite homogeneous country. UAE students felt much more comfortable than Korean students did with online communication. This may be related to a relatively wider use of synchronous meeting tools in the UAE than in Korea. Korean students rarely used them for educational purposes. Online communication using synchronous meeting tools may dramatically reduce misunderstandings and discomfort from the time lag caused by text-based asynchronous communication.

Previous studies revealed that students commonly experience anxiety from relying on 'unknown others', fear of negative evaluation and worries about other group members' negligence (Hilliard et al., 2020). Concerns over privacy and gender are unique to the UAE, while there is the lack of such anxieties in Korea, depicting the unique barriers to online learning and collaboration inherent to more conservative Middle Eastern countries in the Gulf (Osman, 2018). Al-Fadhli (2008) reported that gender is a critical factor to satisfaction of e-learning in Kuwait since online learning could help overcome these cultural limitations, barriers, and challenges by providing alternative means of collaboration without radically changing the social norms. The more positive attitude toward OCL of UAE students could be understood in the same line. While the previous studies indicate that digital access and capabilities is more favorable to male on a global scale (Alaleeli, \& Alnajjar, 2020), the participating college students in Korea and the UAE are not this case. For digital divide, gender would not be a critical factor compared to economic and societal status. 
Language constituted the most important barrier for students in UAE settings and previous research (Hall, 2011; Osman, 2018; Wong, 2004) supports this finding. The UAE is a multicultural expatriate society with diverse language backgrounds. In many cases, the language of pre-university instruction is one other than English. At university, however, students are expected to communicate in English - an expectation that many students fail to meet (Hall, 2011). The use of technology in educational settings is also new to the region (Osman, 2018); thus, it could be expected that students are concerned about the technology skills of peers and the instructor as well as the infrastructure. Interestingly, about $16 \%$ of Korean students indicated that the language is also a barrier for them, even though they use Korean, the mother tongue for most of the students. Perhaps for Korean students, the language problem is not caused by the use of other languages, but may be related to difficulty with text-based asynchronous communication (Lee, 2004). Online interaction is very different from face-to-face interaction in that it does not permit non-verbal communication (Berge \& Collins, 1993) and is also likely to lead misunderstandings (Tu, 2000). To overcome these negative aspects, participants articulate their thoughts, and opinions by using the elaborated expression that requires deep cognitive processing causing cognitive load (Lee, 2004). Two common barriers in Korea and the UAE were concerns about collaboration skills and peers' attitudes; possibly implying the novelty of OCL. Student's attitudes toward OCL can be formed from a complex combination of individual learning motivation, prior OCL experiences, team culture, and team dynamics. Also, social loafing or sucker effect can be present in any group work (Lee, 2014). The instructional design of OCL to reduce those phenomena helps establish a positive team culture.

The assessment of OCL seems to lie in between emphasis on the product versus the process, mirroring the dichotomy in approach found in previous international literature (Child \& Shaw, 2016). Although UAE students regarded assessment of OCL as fairer than did students in Korea, the reasons for that discrepancy are not clear. However, across both contexts, there seems to be room for improvement of assessment. Swan et al. (2006) underscored the importance of utilizing assessment strategies that enhance active participation and address individual accountability (Child \& Shaw, 2016), which can cope with students' discomfort of member's negligence.

Both countries show a similar representation of usage and perceived importance regarding online collaborative activities, although there were slight differences. Among OCL activities, collaborative writing and group exams are the least valued activities and rarely experienced by both countries' students. However, with the forced shift to online learning in the current global pandemic situation, online exams will be indispensable and demands of more diverse online collaborative activities should be addressed even in the campus-based universities. The group presentation and knowledge sharing were the most frequently used and the most important perceived activities. Collaborative writing was expected to be actively implemented with the aid of technology such as Wikis and Google Docs. However, it has not been widely adopted yet because of low awareness of how to use those tools and how to facilitate it (Zhou, Simpson, \& Domizi, 2012). In addition, students are unwilling to make changes or modifications of others' work (Britcliffe \& Walker, 2007) and visibility of all the actions online may create discomfort among users (Lee, 2010). Although most current LMSs include the exam or quiz function, they are not used broadly due to concerns such as security and academic integrity without proctoring (Cluskey, Ehlen, \& Raiborn, 2011). In addition, group online exams apparently involve much more concerns regarding operation and grading. Exams are usually associated with individual accountability and the group-focused version is still considered to be an oxymoron to the majority of students (Hodges, 2004).

While Korean students put more pedagogical value on peer review than UAE students, it seems that the latter prefers and trusts instructor' feedback more, a tendency that is quite prevalent in high power distance societies (Hofstede, 1986; Sayed, 2010). Liu and Carless (2006) reported that the majority of students in Hong Kong showed resistance to peer assessment. There were several reasons behind the phenomena, such as concern for reliability and belief that assessment is the sole responsibility of instructors. Considering that most online courses have more students enrolled than traditional courses, peer feedback can be a practical alternative in higher education to instructor's feedback if students are well trained to provide a quality critique on peer's work. From the pedagogical value, students' ability to evaluate outcomes can be a high cognitive learning objective and peer feedback 
allows students to take an active management role in their own learning (Liu \& Carless, 2006). According to Boud (1995), peer feedback mirrors self-assessment and requires the articulation of what they know about a subject. To promote students' learning, peer feedback can be encouraged. Once students trust peers' capability and observe their feedback equivalent to instructors', peer feedback would be diffused even in a large power distance society.

UAE students also perceive getting more technical and social support than do students in Korea. This might explain the more positive attitude of UAE learners. UAE learners also seem to feel comfortable with being and functioning effectively online as well as having more generous expectations regarding communicating in this way, reflecting the general belief in the important potential of the Internet for formal and informal learning in the region (Vein, 2014). Korean students exhibit higher anxiety towards communication online and have higher expectations regarding the outcomes of these interactions. It can be explained by Koreans' unique Pali-pali (meaning quickly, quickly) culture that appears in all aspects of Korean culture and lifestyle, even in online communication (Lau, Kim, $\&$ Atkin, 2005). Since most current OCL is mediated by asynchronous technology, the time lag between questions and replies is inevitable. By using synchronous technology that enables many-tomany communication, such a concern over misleading communication and inefficiency that many Korean students showed, could be diminished.

IP analysis gives a concise picture of participants' experience by their perceived importance regarding each OCL activity. Korean students want practice exercise to be more frequently used, while UAE students expect group reflection to be implemented more often online. The students in both countries commonly valued understanding course content, presentation, and knowledge sharing, and experienced those activities frequently. They did not appreciate group exams and collaborative writing, which might be due to their limited experience of these activities and concerns over integrity issues of group exams (Cluskey, Ehlen, \& Raiborn, 2011), and reluctance issues of revising others' writing (Britcliffe \& Walker, 2007).

Since group discussion activity is, in fact, a basis of all the other collaborative activities, it is surprising that the students in both countries did not value its educational benefits and wanted to lower its frequency. This indicates that online group discussion was not filled with quality interaction, lacking rationale or evidence that support opinions (Ju, Choi, \& Yoon.,2017; Kim \& Lee, 2019). However, online discussion has been regarded as an effective vehicle for collaborative learning (Swan et al., 2006). Substantial research (Hawisher \& Pemberton, 1997; Jiang \& Ting, 2000) found that successful online collaborative discussion is directly related to its assessment. Undervalued group discussion might be grounded in that it is not properly assessed or appropriately designed and facilitated. In addition, without sufficient training of online discussion or intervention of instructors, and preparation for the discussion, online discussion is hard to bring to an expected outcome.

OCL is being actively adopted in the tertiary classrooms of Korea and UAE's campus-based universities regardless of region and culture. Different cultures bring different expectations about OCL and also some common concerns. Based on the understanding of students' culture, OCL with systemic design that considers barriers, valid and fair assessment of process as well as product, and appropriate support, will offer students with pedagogically sound quality learning experiences with better academic outcomes.

\section{Limitations of Study}

The difficulty in finding an equivalent number of participants caused a limitation of the study. IP analysis of this study was based on the perceptions of students that might be far from the pedagogical values of the activities according to instructional objectives and needs. The results should be interpreted carefully in the context of campus-based university. 


\section{Suggestions or Future Research}

The results suggest a huge variation in attitude across cultures, implying the need for supporting this evidence-based theory grounded instructional approach based on a deeper understanding of the issues through qualitative research with both students and professors. Further research is needed to practically investigate the role of language choice in OCL settings. This is particularly important, as we increasingly communicate across cultures and languages. In addition, with the forced shift to fully online learning in all the campus-based universities due to the recent pandemic situation, the landscape of OCL would be dramatically different from the past. The study of the OCL in diverse countries needs to be implemented in the near future.

Authors' Note: This work was supported by the National Research Foundation of Korea Grant funded by the Korean Government(NRF-2014S1A2A1A01027507)

\section{BIODATA and CONTACT ADDRESSES of AUTHORS}

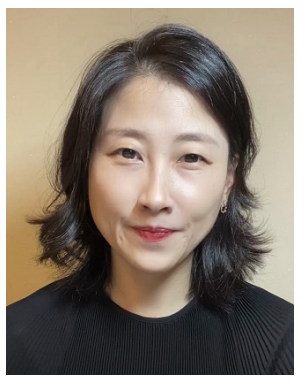

Dr. Jieun LEE is an associate professor at the Department of Education at Chosun University in South Korea. She earned her Ph.D. in Instructional Systems Technology from Indiana University Bloomington, M.Ed. in Educational Technology from Seoul National University, and B.A. in Sociology from Yonsei University. She worked as a marketing specialist at IBM Korea. Her research interests are instructional design for student-centered education, online collaborative learning, instructional consulting to improve student engagement, and teaching expertise development in higher education. She investigated enablers and barriers of instructional design factors for transfer in the workplace as her doctoral dissertation and conducted social network analysis to examine relationships and interactions among participants in online learning environments. She teaches distance education, instructional systems design, educational technology for pre-service teachers.

Jieun LEE

Department of Education, School of Education

Address: Chosun University, 61452, Gwangju, South Korea

Phone: +821073781942

E-mail: jieelee@chosun.ac.kr

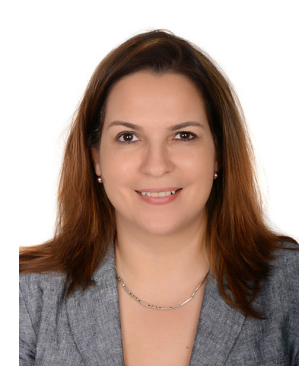

Dr. Gihan OSMAN is assistant professor at the Graduate School of Education \& the Center for Learning and Teaching at the American University in Cairo. Osman's Research interests focus on the role of online learning as a catalyst for educational change and reform in Egypt \& the MENA region. She teaches courses on research methods, assessment, digital literacies, innovative pedagogies, social entrepreneurship, and emerging technologies at the Graduate School of Education Osman has her Ph.D. and MSc in Instructional Systems Technology from Indiana University Bloomington, an M.A. in TEFL from the American University in Cairo, and a BA in English from Alexandria University.

\section{Gihan OSMAN}

Department of International and Comparative Education Address: Graduate School of Education,

American University in Cairo, P.O. Box 74, Cairo, Egypt

Phone: +201271112968

E-mail: gosman@aucegypt.edu 


\section{REFERENCES}

Adam, L. (2003). Information and communication technologies in higher education in Africa: Initiatives and challenges. Journal of Higher Education in Africa, 1(1). 195-211. Retrieved from https:// www.jstor.org/stable/24486119

Adams, M., Rogriquez, S., Zimmer, K. (2019). Studying cultural relevance in online courses: a thematic inquiry. Online Learning, 22(4). http://dx.doi.org/10.24059/olj.v22i4.1262.

Abdul Khalek, J. (2014). High speed Internet and the values of the Arab Spring (The World Bank). Retrieved from https://blogs.worldbank.org/arabvoices/high-speed-internet-and-values-arab-spring

Al-Adwan, A., \& Smedley, J. (2012). Implementing e-learning in the Jordanian higher education system: Factors affecting impact. International Journal of Education and Development using Information and Communication Technology, 8(1), 121-135. Retrieved from https://www.learntechlib. org/p/188017/

Alaleeli, S., \& Alnajjar, A. (2020). The Arab digital generation's engagement with technology: The case of high school students in the UAE. Journal of Technology and Science Education, 10(1), 159-178. https://doi.org/10.3926/jotse.756

Al-Fadhli, S. (2008). Students' perceptions of E-learning in Arab society: Kuwait university as a case study. E-Learning and Digital Media, 5(4), 418-428. doi:10.2304/elea.2008.5.4.418

Al-Harthi, A. S. (2010). Learner self-regulation in distance education: A cross-cultural study. The American Journal of Distance Education, 24(3), 135-150. doi:10.1080/08923647.2010.498232

Angeli, C., Valanides, N., \& Bonk, C. J. (2003). Communication in a web-based conferencing system: The quality of computer-mediated interactions. British Journal of Educational Technology, 34(1), 3143. doi:10.1111/1467-8535.00302

Bates, A.W. (2015). Teaching in a digital age: Guidelines for designing teaching and learning for a digital age. Vancouver, BC: University of British Columbia.

Berge, Z., \& Collins, M. (1993). Computer conferencing and online education. The Arachnet Electronic Journal on Virtual Culture, 1(3), 1-21. Retrieved from http://serials.infomotions.com/aejvc/aejvcv1n03-berge-computer.txt

Boud, D. (1995). Assessment and learning: contradictory or complementary. Assessment for learning in higher education, 35-48.

Bozkurt, A., \& Akbulut, Y. (2019). Dropout patterns and cultural context in online networked learning spaces. Open Praxis, 11(1), 41-54.

Brindley, J. E., Walti, C. \& Blaschke, L. M. (2009). Creating effective collaborative learning groups in an online environment. International Review of Research in Open and Distance Learning, 10(3). doi:10.19173/irrodl.v10i3.675

Britcliffe, W., \& Walker, R. (2007). Making wikis work: How do we create the conditions for effective collaborative learning? ALT-C 2007, 9, 91-92.

Chang, T. T., \& Lim, J. (2002). Cross-cultural communication and social presence in asynchronous learning processes. E-Service, 1(3), 83-105. doi:10.1353/esj.2002.0009

Child, S., \& Shaw, S. (2016). Collaboration in the 21 st century: Implications for assessment. Research Matters, 22 (Summer), 17-22. Retrieved from https://www.cambridgeassessment.org.uk/Images/374626collaboration-in-the-21st-century-implications-for-assessment.pdf

Choi, S., Khamalah, J. N., Kim, M. H., \& Burg, J. E. (2014). Internationalization of a regional campus: Faculty perspectives. International Education, 43(2), 7-24. Retrieved from https://search.proquest. com/openview/376ca5a576fd4b30f663fc891d065b5f

Cluskey Jr, G. R., Ehlen, C. R., \& Raiborn, M. H. (2011). Thwarting online exam cheating without proctor supervision. Journal of Academic and Business Ethics, 4, 1-7.

Culture Compass $^{\mathrm{TM}}$ (2019). Retrieved from https://hi.hofstede-insights.com/the-culture-compass 
Daft, R. L., \& Lengel, R. H. (1986). Organizational information requirements, media richness and structural design. Management Science, 32(5): 554-571. doi:10.1287/mnsc.32.5.554

Economides, A. A. (2008). Culture-aware collaborative learning. Multicultural Education \& Technology Journal.

El-Masri, M., \& Tarhini, A. (2017). Factors affecting the adoption of e-learning systems in Qatar and USA: Extending the unified theory of acceptance and use of technology 2 (UTAUT2). Educational Technology Research and Development, 65(3), 743-763. doi:10.1007/s11423-016-9508-8

Erstad, O., Gilje, Ø., \& de Lange, T. (2007). Re-mixing multimodal resources: Multiliteracies and digital production in Norwegian media education. Learning, Media and Technology, 32(2), 183-198. doi:10.1080/17439880701343394

Fraenkle, J. R., \& Wallen, N. E. (2009). How to design and evaluate research in education. New York: McGrow-Hill.

Gunawardena, C. N. (1998). Designing collaborative learning environments mediated by computer conferencing: Issues and challenges in the Asian socio-cultural context. Indian Journal of Open Learning, 7(1), 101-19. Retrieved from https://www.learntechlib.org/p/86080/.

Hall, E.T. (1976), Beyond culture. Garden City, NY: Doubleday \& Company.

Hall, K. (2011). Teaching composition and rhetoric to Arab EFL learners. In C. Gitsaki (Ed.), Teaching and learning in the Arab world (pp. 421-440). New York: Peter Lang.

Hannon, J., \& D'Netto, B. (2007). Cultural diversity online: Student engagement with learning technologies. International Journal of Educational Management, 21(5), 418-432. doi:10.1108/09513540710760192

Hawisher, G. E., \& Pemberton, M. A. (1997). Writing across the curriculum encounters asynchronous learning networks or WAC meets up with ALN. Journal of Asynchronous Learning Networks, 1(1), 52-72. doi:10.24059/olj.v1i1.1940

Havard, B., Du, J., \& Xu, J. (2008). Online collaborative learning and communication media. Journal of interactive learning research, 19(1), 37-50. Retrieved from

https://www.learntechlib.org/primary/p/22804/.

Henri, F., \& Rigault, C. R. (1996). Collaborative distance learning and computer conferencing. In Advanced educational technology: Research issues and future potential. Springer, Berlin, Heidelberg. doi:10.1007/978-3-642-60968-8_3

Hilliard, J., Kear, K., Donelan, H., \& Heaney, C. (2020). Students' experiences of anxiety in an assessed, online, collaborative project. Computers \& Education, 143, 103675.

Hishina, M., Okada, R., \& Suzuki, K. (2005). Group formation for web-based collaborative learning with personality information. International Journal on e-learning, 4(3), 351-364.

Hodges, L. C. (2004). Group exams in science courses. New Directions for Teaching and Learning, 100, 8993. doi:10.1002/tl.175

Hofstede, G. (1986). Cultural differences in teaching and learning. International Journal of intercultural relations, 10(3), 301-320. http://dx.doi.org/10.1016/0147-1767(86)90015-5

Hofstede Insights (2018). Country comparison. Retrieved from https://www.hofstede-insights.com/ country-comparison/

Human Resource Development of Korea (2019). International cooperation. Retrieved from http://www. hrdkorea.kr/3/5/2/1

Institute of International Education (2018). International students by academic level and place of origin, 2016.2017-2017/2018. Open Doors Reports on International Educational Exchange. Retrieved from http://iie.org/opendoors

Jiang, M., \& Ting, E. (2000). A study of factors influencing students' perceived learning in a web-based course environment. International Journal of Educational Telecommunications, 6(4), 317-338. Retrieved from https://www.learntechlib.org/primary/p/8482/. 
Johnson, D. W., \& R. Johnson. (1986). Computer-assisted cooperative learning. Educational Technology, 26(1), 12-18. Retrieved from https://www.jstor.org/stable/44424559

Ju, H., Choi, I., \& Yoon, B. Y. (2017). Do medical students generate sound arguments during small group discussions in problem-based learning? An analysis of preclinical medical students' argumentation according to a framework of hypothetic-deductive reasoning. Korean journal of medical education, 29(2), 101-109. doi:10.3946/kjme.2017.57

Kim, K. J., \& Bonk, C. J. (2002). Cross-cultural comparisons of online collaboration. Journal of ComputerMediated Communication, 8(1), JCMC814. doi:10.1111/j.1083-6101.2002.tb00163.x

Kim, M., \& Lee, J. (2019). Analysis of interaction in cooperative learning by academic achievement in a middle school English class. Journal of Educational Technology, 35(1), 1-35.

Kirschner, F., Paas, F., \& Kirschner, P. A. (2009). A cognitive load approach to collaborative learning: United brains for complex tasks. Educational psychology review, 21(1), 31-42.

Lakkala, M., Toom, A., Ilomäki, L., \& Muukkonen, H. (2015). Re-designing university courses to support collaborative knowledge creation practices. Australasian Journal of Educational Technology, 31(5), 521-536. doi:10.14742/ajet.2526

Lau, T. Y., Kim, S. W., \& Atkin, D. (2005). An examination of factors contributing to South Korea's global leadership in broadband adoption. Telematics and Informatics, 22(4), 349-359.

Lee, L. (2010). Exploring wiki-mediated collaborative writing: A case study in an elementary Spanish course. Calico Journal, 27(2), 260-276. doi:10.11139/cj.27.2.260-276

Lee, S. (2004). An analysis of interaction patterns in face-to-face and online synchronous/ asynchronous learning environment. Korean Journal of Educational Technology, 20(1), 63-88. doi:10.17232/ KSET.20.1.63

Lee, S. L., Kim, J., Golden, K. J., Kim, J. H., \& Park, M. S. A. (2016). A cross-cultural examination of SNS usage intensity and managing interpersonal relationships online: The role of culture and the autonomous-related self-construal. Frontiers in psychology, 7, 376.

Liu, N. F., \& Carless, D. (2006). Peer feedback: the learning element of peer assessment. Teaching in Higher Education, 11(3), 279-290.

Macdonald, J. (2003). Assessing online collaborative learning: process and product. Computers \& Education, 40(4), 377-391. doi:10.1016/S0360-1315(02)00168-9

Madsen, S. R., \& Cook, B. J. (2010). Transformative learning: UAE, women, and higher education. Journal of Global Responsibility.

Magjuka, R. J., Shi, M., \& Bonk, C. J. (2005). Critical design and administrative issues in online education. Online Journal of Distance Learning Administration, 8(4), 1. Retrieved from https:// www.westga.edu/ - distance/ojdla/winter84/magjuka84.htm

Martin, J. P. (2018). Skills for the 21st Century: Findings and Policy Lessons from the OECD Survey of Adult Skills

Moore, M. G., \& Kearsley, G. (2011). Distance education: A systems view of online learning. Wadsworth: Cengage Learning.

Muukkonen, H., \& Lakkala, M. (2009). Exploring meta skills of knowledge-creating inquiry in higher education. International Journal of Computer-Supported Collaborative Learning, 4(2), 187-211. doi:10.1007/s11412-009-9063-y

Oh, J. C., \& Yoon, S. J. (2014). Predicting the use of online information services based on a modified UTAUT model. Behaviour \& Information Technology, 33(7), 716-729. doi:10.1080/014492 9X.2013.872187

Oliveira, I., Tinoca, L., \& Pereira, A. (2011). Online group work patterns: How to promote a successful collaboration. Computers \& Education, 57(1), 1348-1357. doi:10.1016/j.compedu.2011.01.017

Osman, G. (2018). Formal e-learning in Arab countries: Challenges and opportunities. In M. Spector \& B. Lockee \&, M. Childress (Eds.), Learning, Design \& Technology (pp 1-26). New York: Springer. 
Oye, N. D., Iahad, N. A., \& Rahim, N. A. (2014). The history of UTAUT model and its impact on ICT acceptance and usage by academicians. Education and Information Technologies, 19(1), 251-270. doi:10.1007/s10639-012-9189-9

Palloff, R. M., \& Pratt, K. (1999). Building learning communities in cyberspace (Vol. 12). San Francisco: Jossey-Bass.

Ramiah, C. K. (2014). Emerging trends in electronic learning for library \& information science professionals. In H. K. Kaul, A. Naik \& S. Kaul (Eds.), Knowledge, Library and Information Networking (pp. 328-350). New Delhi: Developing Network.

Sawir, E. (2005). Language difficulties of international students in Australia: The effects of prior learning experience. International Education Journal, 6(5), 567-580.

Sayed, O. H. (2010). Developing business management students' persuasive writing through blog-based peer-feedback. English Language Teaching, 3(3), 54-66. doi:10.5539/elt.v3n3p54

Selinger, M. (2004). Cultural and pedagogical implications of a global e-learning programme. Cambridge Journal of Education, 34(2), 223-239. doi:10.1080/03057640410001700589

Slavin, R. E. (1991). Synthesis of research of cooperative learning. Educational leadership, 48(5), 71-82. Retrieved from https://eric.ed.gov/?id=EJ247023

Swan, K., Shen, J., \& Hiltz, S. R. (2006). Assessment and collaboration in online learning. Journal of Asynchronous Learning Networks, 10(1), 45-62. doi:10.24059/olj.v10i1.1770

Thorpe, M. (2002). Rethinking learner support: The challenge of collaborative online learning. Open learning, 17(2), 105-119. doi: 10.1080/02680510220146887a

Trumbull, E., Rothstein-Fisch, C., \& Greenfield, P. M. (2000). Bridging cultures in our schools: New approaches that work. San Francisco, CA: WestEd.

Tu, C- H. (2000). Critical examination of factors affecting interaction on CMC. Journal of Network and Computer Applications 23, 39-58. doi:10.1006/jnca.1999.0100

Uzuner, S. (2009). Questions of culture in distance learning: A research review. The International Review of Research in Open and Distributed Learning, 10(3). doi:10.19173/irrodl.v10i3.690

Vein, C. (2014). Why increasing digital Arabic content is key for global development? Retrieved from https:// www.theguardian.com/media-network/media-network-blog/2014/apr/28/global-developmentdigital-arabic-content

Wang, M. (2007). Designing online courses that effectively engage learners from diverse cultural backgrounds. British Journal of Educational Technology, 38(2), 294-311. doi:10.1111/j.14678535.2006.00626.x

Wong, J. K. (2004) Are the learning styles of Asian internationals culturally or contextually based? International Education Journal, 4(4), 154-166.

World Bank. (2008). The road not travelled: Education reform in the Middle East and North Africa. Washington, DC: World Bank.

Young, B. J. (2000). Gender difference in student attitudes toward computers. Journal of Research on Computing in Education, 33(2), 204-217. doi:10.1080/08886504.2000.10782310

Zhou, W., Simpson, E., \& Domizi, D. P. (2012). Google Docs in an out-of-class collaborative writing activity. International Journal of Teaching and Learning in Higher Education, 24(3), 359-375.

Zhu, C. (2012). Student satisfaction, performance, and knowledge construction in online collaborative learning. Journal of Educational Technology \& Society, 15(1), 127. Retrieved from https://www. jstor.org/stable/jeductechsoci.15.1.127

Zhu, C., \& Engels, N. (2014). Organizational culture and instructional innovations in higher education: Perceptions and reactions of teachers and students. Educational Management Administration \& Leadership, 42(1), 136-158. doi: 10.1177/1741143213499253 